\title{
PENGARUH PENYULUHAN DENGAN MEDIA AUDIOVISUAL TERHADAP PENGETAHUAN MASYARAKAT TENTANG PENANGANAN MENGHADAPI BENCANA BANJIR DI DESA TANJUNG KECAMATAN HAMPARAN RAWANG PROVINSI JAMBI
}

\author{
Fernalia $^{1^{*}}$, Sela Wahyuni ${ }^{2}$, Hanifah $^{3}$ \\ 1,2,3STIKES Tri Mandiri Sakti, Bengkulu
}

Email korespondensi: lia_fernalia@yahoo.com

\begin{abstract}
THE EFFECT OF COUNSELING USING AUDIOVISUAL MEDIA ON PUBLIC KNOWLEDGE ABOUT HANDLING FLOOD DISASTERS IN TANJUNG VILLAGE, HAMPARAN RAWANG DISTRICT, JAMBI PROVINCE
\end{abstract}

Background: Knowledge is the result of knowing that is obtained by someone after receiving information through the five senses. Good knowledge about handling flood disasters is the first step taken to minimize the impact of floods that occur. Purpose: to study the effect of counseling with audiovisual media on public knowledge about dealing with flood disasters.

Methods: this type of research uses Pre Experiments with the type of The One Group Pretest Posttest Design. The population of this study were all heads of families in Tnajung Village, Hamparan Rawang District. The sampling technique in this study used purposive sampling with inclusion and exclusion criteria so that the number of samples was 77 people. The data collection in this study used primary data techniques by giving questionnaires about knowledge of flood management before and after being given counseling.

Result: the results obtained: Wilcoxom Signed Ranks Test obtained a $Z$ value of 7.688 with an Asymp value. Sig $(p)=0.000$, because the value of $p<0.05$, it can be concluded that there is an effect of providing counseling with audiovisual media on public knowledge about dealing with flood disasters in Tanjung Village, Hamparan Rawang District.

Conclusion: the conclusion of this study can provide experience and learning about research as well as add insight related to the effect of counseling on flood disasters on the community. so that the research results will be better.

Keywords: Counseling, Audiovisual, Flood 
INTISARI: PENGARUH PENYULUHAN DENGAN MEDIA AUDIOVISUAL TERHADAP PENGETAHUAN MASYARAKAT TENTANG PENANGANAN MENGHADAPI BENCANA BANJIR DI DESA TANJUNG KECAMATAN HAMPARAN RAWANG PROVINSI JAMBI

Pendahuluan: Pengetahuan adalah hasil tahu yang didapatkan oleh seseorang setelah menerima informasi melalui panca indera. Pengetahuan yang baik tentang penanganan menghadapi bencana banjir merupakan langkah awal yang dilakukan untuk menimalisir dampak bencana banjir yang terjadi.

Tujuan: mempelajari pengaruh penyuluhan dengan Media Audiovisual terhadap pengetahuan Masyarakat tentang penanganan menghadapi Bencana Banjir.

Metode: Jenis penelitian ini menggunakan Pre Eksperimen dengan jenis The One Group Pretest Posttest Design. Populasi penelitian ini adalah seluruh kepala keluarga di Desa Tnajung Kecamatan Hamparan Rawang. Teknik pengambilan sampel pada penelitian ini menggunakan Purposive Sampling dengan kriteria inklusi dan eksklusi sehingga jumlah sampel sebanyak 77 orang.pengumpulan data dalam penelitian ini menggunakan teknik data primer dengn=an memberikan kuesioner tentang pengetahuan penanganan Banjir sebelum dan setelah diberikan penyuluhan.

Hasil: Hasil penelitian didapatkan : Uji Wilcoxom Signed Ranks Test didapat nilai Z sebesar -7,688 dengan nilai Asymp. Sig $(p)=0,000$, karena nilai $p<0,05$, dengan demikian dapat disimpulkan bahwa ada pengaruh pemberian penyuluhan dengan media audiovisual terhadap pengetahuan Masyarakat tentang penanganan mengahadapi Bencana Banjir di Desa Tanjung Kecamatan Hamparan Rawang.

Kesimpulan: Kesimpulan dari penelitian ini dapat memberikan pengalaman dan pembelajaran tentang penelitian serta menambah wawasan terkait pengaruh penyuluhan tentang bencana banjir pada masyarakat Mengingat keterbatasan penelitian diharapkan agar peneliti selanjutnya dapat melakukan penelitian dengan menggunakan metode penelitian yang lain, menambah variable penelitian, dan menggunakan media yang lebih efektif lagi sehingga hasil penelitian menjadi lebih baik.

Kata Kunci: Penyuluhan, Audiovisual, Banjir

\section{PENDAHULUAN}

Bencana adalah serangkaian peristiwa yang mengancam dan mengganggu kehidupan masyarakat baik yang disebabkan oleh faktor alam non alam, maupun faktor manusia, akibat yang ditimbulkan dari bencana meliputi korban jiwa, kerusakan lingkungan, kerugian harta benda dan dampak psikologis (UU No. 24, 2007). Bencana banjir termasuk bencana terbesar di dunia. Bencana banjir yang terjadi telah membuat orang terkena beberapa ancaman yang menyebabkan kerusakan infrastruktur, kehilangan pekerjaan dan korban jiwa.

Berdasarkan data yang diperoleh dari badan pengkajian dan penerapan teknologi (BPPT, 2010) kejadian dan korban banjir menempati urutan pertama di dunia dari berbagai bencana alam lain, yaitu mencapai 55\%. Sebagian kota-kota besar di daerah industri penting serta daerah pertanian yang subur di dunia berada didataran banjir seperti New York, Tokyo, Osaka, Bangkok, Amsterdam dan sebagainya. 
Indonesia merupakan salah satu negara yang tergolong rawan terhadap terjadi nya bencana alam. Secara goografis Indonesia merupakan negara kepulauan yang terletak pada pertemuan empat lempeng tektonik. yaiu lempeng benua Asia, benua Australia, samudera Hindiadan samudera Pasifik Pada bagian selatan dan timur Indonesia terdapat sabuk vulkanik (volcanic arc) yang memanjang dari pulau Sumatera Jawa, Nusa Tenggara dan Sulawesi yang sisinya berupa pegunungan vulkanik dan dataran rendah. Kondisi sersebut sangat berpotensi sekaligus terjadinya rawan bencana seperti letusan gunung berapi, gempa bumi, tsunami, banjir dan tanah longsor (Alzahrani \& Kyratais, 2017).

Berdasarkan data Badan Penanggulangan Bencana (BNPB, 2019) bencana terbanyak yang terjadi di indonesia adalah bencana hidrometereologi yang didomisili oleh tanah longsong, banjir, puting beliung, dan gempa bumi. Data kejadian bencana yang dilaporkan oleh badan penanggulangan bencana (BNPB) menunjukkan bahwa pada tahun 2013 terdapat 525 kejadian banjir di indonesia. Data tahun 2014 menunjukkan adanya penurunanan menjadi kurang lebih 478 kejadian dan pada tahun 2015 naik kembali menjadi 485 kejadian. Hingga tahun 2016 kejadian bencana banjir terus meningkat dan merupakan bencana dengan frekuensi kejadian paling tinggi diantara bencana-bencana lain yaitu dengan total 766 kejadian (Nugroho, 2016).

Bencana banjir merupakan peristiwa terjadinya genangan pada daerah yang biasanya kering yang merupakan kejadian hidrologis yang dicirikan dengan debit dan atau muka air yang tinggi dan dapat menyebabkan pengenangan pada lahan di sekitar sungai, danau ataupun sistem air lainnya (Dodon 2013).

Menurut data (BNPB,2013) menunjukkan pada akhir desember 2013 terdapat 85 kejadian banjir yang menyebar di 21 provinsi dari 34 provinsi diindonesia. Provinsi jambi termasuk didalam 5 besar provinsi dengan kejadian banjir yang cukup tinggi, 5 provinsi tersebut antara lain jawa timur, jawa barat, jawa tengah, riau, jambi dan sumatra utara. Provinsi jambi sebagai salah satu provinsi di sumatra yang terkenal dengan iklim tropis. Secara klimatologi provinsi jambi memiliki iklim tropis, sepanjang tahun 2014, provinsi jambi memiliki curah hujan yang bervariasi, mulai dari curah hujan sedang hingga sangat tinggi. Curah hujan rata-rata pada tahun 2014 di provinsi jambi adalah 120-180 mm. Curah hujan bulanan tertinggi ditemukan pada bulan maret dan november (1.383-1.405 mm/bulan). Selain curah hujan yang tinggi jambi memiliki sungai yang besar yaitu sungai batang hari yang mengaliri hampir seluruh daerah yang ada di provinsi jambi. Selama tahun 2014 bencana alam yang terjadi di provinsi jambi masih didomisili oleh banjir dan kebakaran hutan dan lahan. Didapatkan data dari badan penanggulangan bencana daerah (BPBD,2014) provinsi jambi sepanjang tahun 2014 banjir telah terjadi di 9 wilayah kabupaten/kota diprovinsi jambi, salah satunya desa tanjung yang berada di kota sungai penuh (Eltha, 2020).

Data yang diperoleh dari pusat data informasi dan humas BNPB (2016), menyatakan bahwa hingga bulan november 2016 tercatat dampak kerugian yang ditimbulkan oleh bencana telah menyebabkan 522 
orang meninggal dunia dan hilang, 3,05 juta jiwa mengungsi dan menderita ,69,289 unit rumah rusak dimana 9.171 rusak berat, 13.077 rusak sedang, 47.039 rusak ringan dan 2.311 unit fasilitas umum rusak. Total korban tersebut berasal dari berbagai kejadian bencana namun di dominasi oleh kejadian banjir dengan 766 kejadian yang menyebabkan 147 jiwa meninggal dunia, 107 jiwa luka, 2,72 juta jiwa mengungsi dan menderita serta 30.669 rumah rusak.

Peran serta dari masyarakat sangat dibutuhkan dalam mengurangi dampak bencana oleh karena itu masyarakat harus memiliki pengetahuan yang cukup sehingga bisa menghadapi bencana yang akan terjadi. Adapun faktor utama yang dapat menimbulkan korban dan kerugian yang besar dari bencana banjir yaitu dikarenakan kurangnya pemahaman tentang karakteristik bahaya, sikap atau prilaku masayarakat itu sendiri yang mengakibatkan masyarakat tidak siap terhadap bencana yang datang (Rosyda, 2017). Salah satu upaya yang dapat dilakukan untuk meningkatkan pengetahuan dan menumbuhkan sikap kepedulian masyarakat dalam menghadapi bencana yaitu dengan memberikan pendidikan kesehatan terhadap masyarakat agar masyarakat memiliki pengetahuan yang cukup dalam menghadapi bencana.

Pengetahuan adalah faktor utama dalam kesiapan menghadapi bencana banjir. Pengetahuan yang dimiliki seseorang dapat mempengaruhi sikap dan kepedulian terhadap kesiapan dalam menghadapi bencana terlebih terhadap peran kepala keluarga dalam menghadapi bencana sangatlah penting karena kepala keluarga berperan dalam menyampaikan informasi untuk semua keluarganya, mengambil keputusan yang cepat dapat mempengaruhi keluarga. Kepala keluarga merupakan sumber dukungan sosial bagi keluarga, besarnya pengaruh tindakan ucapan serta tingkah laku kepala keluarga akan menjadikan panutan bagi keluarga, kemampuan harus dimiliki kepala keluarga dalam menghadapi bencana banjir harus mempunyai pengetahuan dan sikap terhadap bencana itu sendiri seperti kesiapan terhadap bencana, kesiapan menghadapi bencana, akan menunjukkan adanya sikap dan pengetahuan dalam menghadapi bencana (Harahap, 2015).

Meningkatkan pengetahuan serta menumbuhkan sikap kepedulian masyarakat dalam menghadapi bencana banjir dan mengurangi dampak yang terjadi yaitu dengan memberikan penyuluhan atau pendidikan kesehatan yang disampaikan dalam bentuk vidio sehingga bisa menarik perhatian dan memotivasi masyarakat. Media audio visual dirasa sangat tepat untuk menyampaikan pesan kepada masyarakat penyampaiannya yang lebih bervariasi, tidak hanya menggunakan komunikasi verbal melalui penuturan kata-kata penulis masyarakat akan lebih mengamati tidak hanya mendengar saja (Simamora, 2019). Sehingga dari hasil yang diamati masyarakat dapat menerapkan apa yang telah disampaikan melalui media audiovisual sehingga dapat menumbuhkan motivasi masyarakat dalam mengahadapi bencana banjir.

Berdasarkan paparan diatas, maka penulis tertarik untuk mmengadakan penelitian mengenai pengaruh penyuluhan dengan media audiovisual terhadap pengetahuan masyarakat menghadapi bencana 
banjir di desa tanjung kecamatan hamparan rawang.

\section{METODE PENELITIAN}

Penelitian ini dilaksanakan di Desa Tanjung Kecamatan Hamparan rawang. Desain penelitian yang digunakan dalam penelitian ini adalah penelitian kuantitatif dengan menggunakan pre eksperiment dengan jenis pre test dan post test one group design. Populasi dalam penelitian ini adalah jumalah keseluruhan kepala keluarga di Desa Tanjung Kecamatan Hamparan Rawang yang berjumlah 329 KK. Teknik pengambilan sampel dalam penelitian ini adalah menggunakan nonprobablility sampling dengan teknik purposive sampling sehingga didapatkan jumlah sampel sebanyak 77 kk.Teknik pengumpulan data yang digunakan dalam penelitian ini adalah menggunakan data primer dan data sekunder. Data primer yaitu data yang diperoleh langsung dari responden melalui penyebaran kuesioner dan untuk penyuluhan tentang bencana banjir menggunakan media vidio, sebelum penyebaran kuesioner dikaji dulu tingkat pengetahuan Masyarakat Desa Tanjung tentang bencana banjir. Setelah penyebaran kuesioner kemudian penayangan vidio selama 13:34 menit dengan materi penyuluhan yang meliputi pemahaman tentang bencana banjir, jenis-jenis banjir, penyebab banjir, wilayah rentan banjir, cara penangaanan banjir baik sebelum terjadinya banjir,saat terjadinya banjir maupun setelah terjadinya banjir tersebut, setelah penayangan vidio akan dikaji ulang untuk mengetahui tingkat Pengetahuan Masyarakat Desa Tanjung dalam menghadapi Bencana Banjir. Data sekunder berupa data yang diperoleh dengan cara menelusuri dan memilih literatur, serta data yang diperoleh dari Kantor Kepala Desa Tanjung Kecamatan Hamparan Rawang. Teknik analisisa data menggunakan analisis univariat, normalitas dengan uji KolmogorowSmirnovTest dan analisis bivariate dengan uji Uji Wilcoxom Signed Rank Test. Pengolahan data menggunakan aplikasi SPSS.

HASIL

Tabel 1

Gambaran Pengetahuan Masyarakat Tentang Penanganan Menghadapi Bencana Banjir Sebelum Dan Setelah Diberikan Penyuluhan Di Desa Tanjung Kecamatan Hamparan Rawang

\begin{tabular}{cccccc}
\hline & N & Mean & $\begin{array}{c}\text { Std. } \\
\text { Deviation }\end{array}$ & Minimum & Maximun \\
\hline $\begin{array}{c}\text { Pengetahuan } \\
\text { Sebelum } \\
\text { Penyuluhan }\end{array}$ & 77 & 9.25 & 1.574 & 5 & 13 \\
\hline $\begin{array}{c}\text { Pengetahuan } \\
\text { Sesudah } \\
\text { Penyuluhan }\end{array}$ & 77 & 12.69 & 1.369 & 9 & 16 \\
\hline
\end{tabular}


Berdasarkan tabel 1, tampak bahwa dari 77 responden sebelum dilakukan penyuluhan didapatkan pengetahuan tentang penanganan bencana banjir dengan nilai minimum 5 , nilai maksimum 13 , nilai rata-rata 9,25 dengan Std. Deviation 1,574. sedangkan setelah dilakukan penyuluhan didapatkan pengetahuan tentang penanganan bencana banjir dengan nilai minimum 9 , nilai maksimum 16, nilai rata-rata 12,69 dengan Std. Deviation 1,369.

Tabel 2

Uji Normalitas Data Di Desa Tanjung Kecamatan Hamaparan Rawang Tingkat Pengetahuan Kolmogorov-Smirnov

\begin{tabular}{cccc}
\cline { 2 - 4 } & Statistic & Df & Sig. \\
\hline $\begin{array}{c}\text { Pengetahuan sebelum } \\
\text { penyuluhan }\end{array}$ & 191 & 77 & 000 \\
\hline $\begin{array}{c}\text { Pengetahuan sesudah } \\
\text { penyuluhan }\end{array}$ & 165 & 77 & 000 \\
\hline
\end{tabular}

Berdasarkan tabel 2, uji normalitas data menggunakan uji Kolmogorov-Smirnov diperoleh hasil bahwa pengetahuan sebelum diberikan penyuluhan tidak berdistribusi normal dengan nilai $p$ (sig) $<0,05$ dan pengetahuan sesudah diberikan penyuluhan juga tidak berdistribusi normal dengan nilai $p$ (sig) $<0,05$. Karena semua nilai $p$ (sig) $<$ 0,05 maka pengetahuan sebelum penyuluhan dan sesudah penyuluhan dikatakan berdistribusi tidak normal. Karena kedua kelompok data tidak berdistribusi normal maka digunakan uji Wilcoxon Signed Rank Test.

Tabel 3

Uji Wilcoxom Signed Rank Test di Desa Tanjung Kecamatan Hamparan Rawang

\begin{tabular}{ccccccc}
\hline & $\mathrm{N}$ & $\begin{array}{c}\text { Mean } \\
\text { Rank }\end{array}$ & $\begin{array}{c}\text { Sum of } \\
\text { Ranks }\end{array}$ & Z & $\begin{array}{c}\text { Asymp. } \\
\text { Sig. (2- } \\
\text { tailed) }\end{array}$ \\
\hline $\begin{array}{c}\text { Pengetahuan sesudah } \\
\text { penyuluhan }\end{array}$ & $\begin{array}{c}\text { Negative } \\
\text { Rank }\end{array}$ & $0^{\mathrm{a}}$ & .00 & .00 & & \\
\cline { 2 - 7 } $\begin{array}{c}\text { Pengetahuan sebelum } \\
\text { penyuluhan }\end{array}$ & $\begin{array}{c}\text { Positive } \\
\text { Rank }\end{array}$ & $77^{\mathrm{b}}$ & 39.00 & 3003.00 & $-7.688^{\mathrm{b}}$ & .000 \\
\cline { 2 - 7 } & Ties & $0^{\mathrm{c}}$ & & & & \\
\cline { 2 - 7 } & Total & 77 & & & & \\
\hline
\end{tabular}

Berdasarkan tabel 3, Berdasarkan hasil Uji Wilcoxom Signed Rank Test pada tabel 3, diperoleh statistik $\mathrm{Z}=-7,688$ dengan $\mathrm{p}(\mathrm{sig})=$ 0,000 . karena nilai $p(\mathrm{sig})<0,05$. Jadi signifikan Ho ditolak dan Ha diterima, artinya ada pengaruh penyuluhan dengan media audiovisual terhadap pengetahuan masyarakat tentang penanganan bencana banjir di Desa Tanjung Kecamatan Hamparan Rawang Provinsi Jambi 


\section{PEMBAHASAN}

Berdasarkan hasil penelitian tampak bahwa 77 responden sebelum diberikan penyuluhan didapatkan pengetahuan tentang penanganan menghadapi bencana dengan nilai minimum 5 , nilai maksimum 13 , nilai rata-rata 9,25 dengan Std. Deviation 1,574 .

Hal ini disebabkan responden kurang terpaparnya informasi dan kurang mendapatkan penyuluhan atau sosialisai tentang penanganan banjir. Selain itu sebagian responden memiliki tingkat pendidikan yang kurang baik, hal ini dibuktikan dengan adanya salah satu responden dari tingkat pendidikan SD yang hanya mampu menjawab 5 pertanyaan yang diberikan oleh peneliti ini berdasarkan pengetahuan yang dimiliki oleh responden sebelumnya. Disini dapat peneliti simpulkan bahwa pendidikan sangat mempengaruhi seseorang untuk mendapatkan pengetahuan dan menerima informasi secara baik.

Menurut Nursalam (2011), pendidikan sangat diperlukan untuk mendapatkan informasi sehingga dapat mempengaruhi, makin tinggi pendidikan seseorang semakin mudah untuk menerima informasi yang disampaikan. Semakin tinggi tingkat pendidikan seseorang semakin banyak pula pengetahuan yang dimiliki. Sebaliknya semakin pendidikan yang kuraang akan menghambat perkembangan seseorang terhadap nilai-nilai yang baru diperkenalkan.

Hasil penelitian ini sejalan dengan pendapat Eberhardt et al (2007), yang melakukan penelitian terhadap 74 responden dengan latar belakang pendidikan yang berbeda dan dihubungkan dengan tingkat pengetahuan. Hasilnya adalah mereka yang memiliki pendidikan dengan level lebih tinggi memiliki tingkat pengetahuan yang lebih luas dan pengalaman yang banyak. Hal ini juga berpengaruh terhadap kemampuan kognitif seseorang.

Menurut Carter (2011), bahwa semakin tinggi tingkat pendidikan seseorang akan semakin mudah menerima informasi sehingga semakin banyak pula pengalaman yang dimiliki, dalam hal ini khususnya pengetahuan tentang penanganan menghadapi bencana banjir. Seseorang yang memiliki pengalaman yang luas akan berdampak pada kognitifnya. Pendidikan merupakan faktor yang semakin penting dalam kehidupan sehari-hari. Tingkat pendidikan akan mempengaruhi persepsi seseorangtentang kognitif. Seseorang yang berpendidikan tinggi juga memiliki penalaran yang tinggi pula.

Berdasarkan hasil penelitian Sesudah diberikan penyuluhan tentang penanganan menghadapi bencana banjir didapatkan nilai minimum pengetahuan masyarakat yaitu 9, maksimum 16 dengan nilai rata-rata 12.69 dengan Std. Deviation 1.369. Berdasarkan hasil penelitian didapatkan skor nilai mean difference yaitu 3,44 arti skor pengetahuan sesudah diberikan penyuluhan lebih besar dibandingkan dengan pengetahuan sebelum diberikan penyuluhan, maka dapat disimpulkan terdapat peningkatan pengetahuan sesudah diberikan panyuluhan ratarata peningkatan 3,44. Menurut peneliti hal ini disebabkan oleh meningkatnya pengetahuan masingmasing responden dalam mendapatkan informasi yang disampaikan, hal ini terlihat saat dilakukan penelitian semua responden sangat antusias untuk mengikuti penyuluhan, selain itu responden 
sangat tertarik untuk memperhatikan vidio yang dibuat oleh peneliti dengan menarik sebagai media yang digunakan untuk menyampaikan informasi.

Hasil penelitian ini sejalan dengan pendapat Masita Malahika, Sefty Rompas dan Jeavery Bawotang (2016), faktor informasi yang didapatkan dari pendidikan kesehatan merupakan faktor utama yang mempengaruhi pengetahuan tentang bencana terhadap masyarakat. Penelitian tersebut menjelaskan bahwa sebelum diberikan pendidika kesehatan masyarakat kurang mengetahui tentang kesiapan menghadapi bencana banjir dan sesudah deberikan pendidikan kesehatan pengetahuan masyarakat bertambah.

Menurut Febliza Hayati (2017), menyatakan bahwa media audiovisual merupakan proses untuk meningkatkan pengetahuan dengan cara mendengarkan suara sekaligus melihat gambar yang ditampilkan. Sehingga bisa memberikan bukti yang konkrit atas apa yang sedang diajarkan agar seseorang tersebut bisa membandingkan, memahami, mengingat serta dapat mengaplikasikan pada kehidupannya.

Yuliaonto (2020), menjalaskan bahwa fungsi dari media audiovisual yaitu mampu memberikan rangsangan yang bervariasi pada otak sehingga otak dapat berfungsi secara optimal, dapat menghasilkan seragaman pengamatan, membangkitkan motivasi dan merangsang untuk belajar dan mampu memberikan kesempatan untuk belajar mandiri dengan menganalisa apa yang dilihat dan didengar.

Hasil penelitian ini juga sejalan dengan penelitian Rohana (2016), menunukkan bahwa setelah dilakukan pendidikan kesehatan dengan metode vidio terdapat peningkatan pengetahuan yaitu terdapat $78,7 \%$ responden memiliki pengetahuan baik dan $21,3 \%$ responden memiliki pengetahuan cukup sedangkan siwa yang memiliki pengetahuan kurang tidak ada.

Hasil uji Wilcoxom didapat ada pengaruh yang signifikan penyuluhan dengan media audiovisual terhadap pengetahuan masyarakat tentang penanganan menghadapi bencana banjir di Desa Tanjung Kecamatan Hamparan Rawang Provinsi Jambi.

Menurut Hayati (2017), media audiovisual merupakan suatu media yang digunakan untuk digunakan dalam menyampaikan suatu pembelajaran dengan menggunakan unsur suara dangambar yang mana dapat dilihat seperti rekaman vidio, slide suara, film dan lain sebagainya yang melibatkan indera penglihatan dan indera pendengaran sehingga mampu tercapainya tujuan dalam menyampaikan informasi atau pembelajaran. Dengan adanya penyuluhan yang dilakukan dengan media audovisual yang sangat efektif digunakan untuk menyampaikan suatu pembelajaran sehingga pesan yang disampaikan mudah di terima oleh orang lain, maka akan meningkatkan pengetahuan semua masyarakat yang mendapatkan penyuluhan sehingga mampu menangani bencana banjir.

Menurut saleh yang dikutip dari Chifdilah (2021), media audiovisual adalah media yang menyediakan informasi melalui aspek audio dan visual sehingga menyediakan informasi yang lebih menarik. Hal ini akan memicu sasaran memanfaatkan indara penglihatan dan pendengarannya dalam menerim informasi yang disampaikan melalui media audiovisual. Karakteristik tersebut 
mampu menarik perhtian sasaran untuk lebih fokus dalam mengikuti proses transfer informasi.

Penelitian ini sejalan dengan penelitianyang dilakukan Kumboyono (2011), yang meneliti tentang perbedaan efek penyuluhan menggunakan media cetak dan media audiovisual terhadap peningkatan pengetahuan pasien tuberkulosis. Didapatkan bahwa penyuluhan kesehatan menggunakan media audiovisual lebih baik dari pada penyuluhan kesehatan menggunakan media cetak yang dilihat dar inilai rata-rata media audiovisual lebih tinggi yaitu 23,8 dibandingkan dengan

\section{KESIMPULAN}

1. Pengetahuan masyarakat sebelum diberikan penyuluhan tantang penanganan menghadapi bencana banjir minimum nilai 5 sebayak 1 orang, nilai maksimum 13 sebanyak 1 orang, nilai rata-rata 9,25 dengan Std. Deviation 1,574.

2. Pengetahuan masyarakat sesudah diberikan penyuluhan tantang penanganan menghadapi bencana banjir minimum nilai 9 sebayak 1 orang dan nilai maksimum 16 sebanyak 1 orang, nilai rata-rata 12,69 dengan Std. Deviation 1,369 .

3. Ada pengaruh penyuluhan dengan media audiovisual terhadap pengetahuan masyarakat tentang penanganan menghadapi bencana banjir di Desa Tanjung Kecamatan Hamparan Rawang..

\section{SARAN}

$$
\text { Diharapkan Kepada }
$$
masyarakat Desa Tanjung untuk selalu aktif mengikuti kegiatan yang diadakan oleh pemerintahan desa terutama dalam bidang penanganan media cetak yaitu 22,0 dengan nilai (signifikansi) hasil uji tindependent $0,0009(p<0,05)$.

Dari penelitian yang dilakukan terhadap masyarakat Desa Tanjung Kecamatan Hamparan Rawang sebagai seseorang tenaga kesehatan harus lebih banyak mengetahui pengetahuan yang berhubungan dengan disaster sehingga memiliki pengetahuan yang luas dan bisa menerapkannya terhadap masyarakat atau menginformasikan kepada masyarakat sehingga bisa mencegah dan memanimalisir dampak dari bencana tersebut.

bencana sehingga masyarakat mendapatkan informasi yang bermanfaat untuk menjadi acuan dalam meningkatkan pengetahuan masyarakat dalam menangani bencana banjir serta meningkatkan kesadaran masyaraat dalam hal kebencanaan.

\section{DAFTAR PUSTAKA}

Adam, S. (2015). Pemanfaatan media pembelajaran berbasis teknologi informasi bagi siswa kelas X SMA Ananda Batam. Computer Based Information

System Journal, 3(2).

Al Muhtarom, N. I. M. (2015). Hubungan Antara Pengetahuan Dengan Sikap Masyarakat Dan Anggota Forum Desa Tangguh Bencana Terhadappenanganan Banjir Di Desa Sidounder Kecamatan Puring Kabupaten Kebumen (Doctoral Dissertation, Stikes Muhammadiyah Gombong). 
Anggraini, A., Triansyah, A., \& Hidasari, F. P. (2018). Pengaruh Media Pembelajaran Audio Visual Keterampilan Forehand Drive Tenis Meja Penjas Fkip Untan 2016. Jurnal pendidikan dan pembelajaran khatulistiwa, 7(7).

Arif, M. (2019). Analisis Wilayah Berpotensi Banjir Daerah Sumatera Barat Untuk Pelaksanaan Pembelajaran Geografi Berorientasi Bencana Alam. Jurnal Kepemimpinan Dan Pengurusan Sekolah, 4(1), 5360.

Aryono, D. P. (2011). The Silent Disaster Bencana dan Korban Massal. CV. Sagung Seto. Jakarta.

Azwar, S. (2011). Sikap manusia: teori dan pengukurannya. Yogakarta: Pustaka Pelajar

Badan Penanggulangan Bencana Daerah (BPBD) Kota Sungai Penuh. (2019). "RENSTRA. Rencana Strategis Badan Penanggulangan Bencana Daerah". Badan Penanggulangan Bencana Daerah.

Bidang Komunikasi dan Informasi Lingkungan dan Pemberdayaan Masyarakat. Laporan Status Lingkungan Hidup Daerah Provinsi Jambi Tahun 2014. Jambi: Badan Lingkungan Hidup Daerah Provinsi Jambi; 2014.

BNPB (2019). Data Informasi Bencana Indonesia (Dibi) (Internet). Badan Nasional Penanggulangan Bencana. (2019). (Diakses Tanggal 25 Februari 2019). Diambil Dari: Http://Bnpb.Cloud/Dibi.

BNPB. (2013). Informasi Kebencana Bulanan Teraktual Edisi Desember 2013. In: Badan
Nasional Penanggulangan Bencana, editor. Jakarta: BNPB. BPBD Sungai Penuh. (2015). Sejarah Kejadian Bencana Selama 3 Tahun Terakhir (2013 s/d 2015). In: BPBD Sungai Penuh, editor. Sungai Penuh: BPBD Sungai Penuh; 2015.

BPBD Sungai Penuh. Sejarah Kejadian Bencana Selama 3 Tahun Terakhir (2013 s/d 2015). In: BPBD Sungai Penuh, editor. Sungai Penuh: BPBD Sungai Penuh; 2015.

Chyntia, A. P. (2017). Faktor Yang Berhubungan Dengan Kesiapsiagaan Keluarga Terhadap Bencana Banjir Di Sungai Penuh Tahun 2017 (Doctoral Dissertation, Universitas Andalas).

Chifdillah, N A \& Hazanah, S. (2021). Perbedaan Pengaruh Pendidikan Kesehatan dengan Media Audiovisual dan Media Visual Terhadap Pengetahuan Mahasiswa. Mahakam Midwifery Journal, 6 (1), 14-27.

Danianti, R. P., \& Sariffuddin, S. (2015). Tingkat kerentanan masyarakat terhadap bencana banjir di Perumnas Tlogosari, Kota Semarang. Jurnal Pengembangan Kota, 3(2), 9099.

Darmawan, D., \& Fadjarajani, S. (2016). Hubungan Antara Pengetahuan dan Sikap Pelestarian Lingkungan Dengan Perilaku Wisatawan dalam Menjaga Kebersihan Lingkungan (Studi di Kawasan Objek Wisata Alam Gunung Galunggung Desa Linggajati Kecamatan Sukaratu Kabupaten Tasikmalaya). Jurnal Geografi, 4(1)

Darwis, D., Ardi, M., \& Pertiwi, N. (2020). Pengaruh Pengetahuan 
dan Sikap Ibu Tentang Gizi Terhadap Pemberian Makanan Bergizi Balita. UNM Environmental Journals, 3(1), 01-08.

Dinas Kesehatan Sungai Penuh (2015). Form Pelaporan Perkembangan Kejadian Bencana. In: Dinas Kesehatan Sungai Penuh, editor. Sungai Penuh: Dinas Kesehatan Sungai Penuh; 2015.

Dodon, Y. (2013). "Indikator dan Perilaku Kesiapsiagaan Masyarakat Di PemukimanPadat Penduduk Dalam Antisipasi Berbagai Fase Bencana Banjir". Jurnal Perencanaan Wilayah dan Kota, Vol.24 No.2 (Agustus2013):h.125-140.

Effendi, H. (2009). Perbedaan motivasi belajar siswa yang berasal dari keluarga utuh dengan siswa yang berasal dari keluarga broken home di SMK Negeri 2 Malang (Doctoral dissertation, Universitas Negeri Malang).

Findayani, A. (2018). Kesiap Siagaan Masyarakat Dalam Penanggulangan Banjir Di Kota Semarang. Jurnal Geografi: Media Informasi Pengembangan Dan Profesi Kegeografian, 12(1), 102-114.

Harahap, M. E., Lufti, M. L., \& Muthalib, A. (2015). Pengaruh Pengetahuan Dan Sikap Terhadap Kesiapsiagaan Masyarakat Dalam Menghadapi Bencana Banjir Di Desa Perkebunan Bukit Lawang Kecamatan Bahorok Tahun 2011. Jurnal Ilmiah Keperawatan Imelda, 1(1), 2231.

Hasan, S. (2012). Strategi Krisis Public Relations Pasca Bencana. Jurnal
Dialog dan Penanggulangan Bencana, 3(2), 68-78.

Hayati, N., \& Harianto, F. (2017). Hubungan Penggunaan Media Pembelajaran Audio Visual Dengan Minat Peserta Didik Pada Pembelajaran Pendidikan Agama Islam Di Sman 1 Bangkinang Kota. Al-Hikmah: Jurnal Agama Dan Ilmu Pengetahuan, 14(2), 160-180.

Hildayanto, A. (2020). Pengetahuan Dan Sikap Kesiapsiagaan Masyarakat Terhadap Bencana Banjir. Higeia (Journal Of Public Health Research And Development), 4(4), 577-586.

Indawati, L. (2015). Analisis Tingkat Kerawanan Banjir Dan Persepsi Masyarakat Terhadap Upaya Pengurangan Dampak Banjir Di Kecamatan Baureno Kabupaten Bojonegoro (Implementasinya Sebagai Sumber Belajar Siswa Kelas 7 Smpn 2 Baureno, Pada Topik: Keadaan Alam Dan Aktifitas Pendu (Doctoral Dissertation, Uns (Sebelas Maret University)).

Kadek, A. (2018). Pengaruh Penyuluhan Kesehatan Dengan Media Vidio Terhadap Pengetahuan Dan Sikap Persinonal Hygiene Siswa Sd Negeri 2 Karya Makmur Kabupaten Musi Rawas Utara. Skripsi. Bengkulu. (Sekolah Tinggi Ilmu Kesehatan Tri Mandiri Sakti Bengkulu)

Lestari, S. (2015). Tingkat Pengetahuan Ibu Tentang Diare Pada Balita Di Desa Baturetno Banguntapan Bantul Yogyakarta.

Mahnun, N. (2018). Implementasi pembelajaran online dan optimalisasi pengelolaan pembelajaran berbasis online di Perguruan Tinggi Islam dalam 
mewujudkan World Class University. IJIEM: Kajian Teori dan Hasil Penelitian Pendidikan, 1(1), 29-36.

Mandasari, N., \& Ip, S. (2020). Penanggulangan Bencana Banjir Di Sungai Batang Merao Pada Badan Penanggulangan Bencana Daerah Kota Sungai Penuh. Jurnal Administrasi Nusantara, 3(2), 43-51.

Mayzufli, A., Respati, T., \& Budiman, B. (2013). Pengetahuan, Sikap, dan Perilaku Mengenai Kesehatan Reproduksi Siswa SMA Swasta dan Madrasyah Alliyah. Global medical \& health communication, 1(2), 46-51.

Newcomb, T., R. Turner \& $P$. Converse. (1985). Social Psychologi: The Study of Human Interaction. New York: Holt Rinehart and Winston, Inc.

Notoatmodjo, S. (2010). Metodologi penelitian kesehatan. Jakarta: Rineka Cipta

Notoatmodjo, S. (2012). Promosi Kesehatan dan Ilmu Perilaku, Rineka Cipta, Jakarta

Notoatmojo Soekidjo. (2017). Metedologi Penelitian Kesehatan. Jakarta: Rineka Cipta

Nurrita, T. (2018). Pengembangan Media Pembelajaran Untuk Meningkatkan Hasil Belajar Siswa. Misykat: Jurnal Ilmu-Ilmu Al-Quran, Hadist, Syari'ah Dan Tarbiyah, 3(1), 171.

Nursalam. (2011). Konsep dan Penerapan Metodologi Penelitian IImu Keperawatan. Jakarta: Salemba Medika

Ridha, R., \& Husna, C. (2017). Pengetahuan Dan Sikap Masyarakat Terhadap Tindakan Penanggulangan Banjir. Jurnal
Ilmiah Mahasiswa Fakultas Keperawatan, 2(4).

Rosyida, F., \& Adi, K. R. (2017). Studi Eksplorasi Pengetahuan Dan Sikap Terhadap Kesiapsiagaan Bencana Banjir Di Sd Pilanggede Kecamatan Balen Kabupaten Bojonegoro. Jurnal Teori Dan Praksis Pembelajaran Ips, 2(1), 1-5.

Simamora, R. H., \& Saragih, E. (2019). Penyuluhan kesehatan terhadap masyarakat: Perawatan penderita asam urat dengan media audiovisual. JPPM (Jurnal Pendidikan dan Pemberdayaan Masyarakat), 6(1), 24-31.

Sugiyono. (2011). Metodologi Penelitian Kuantitatif Kualitatif dan R\&D. Bandung:Alfabeta

Tafonao, T. (2018). Peranan Media Pembelajaran Dalam Meningkatkan Minat Belajar Mahasiswa. Jurnal Komunikasi Pendidikan, 2(2), 103-114.

Tahir, M. R., Rahman, U., \& Nursalam, N. (2015). Pengaruh Kecemasan dan Kesulitan Belajar Matematika Terhadap Hasil Belajar Matematika Pada Siswa Kelas X MA Negeri 1 Watampone Kabupaten Bone. MaPan: Jurnal Matematika dan Pembelajaran, 3(1), 86-102.

Taniredja, T., \& Mustafidah, H. (2011). Penelitian Kuantitatif (Sebuah Pengantar). Bandung: Alfabeta.

Undang-Undang Ri No. 24 Tahun 2007 Tentang Penanggulangan Bencana. (2007. Jakarta.

United Nations (2000). Guidelines for Reducing Flood Losses. In: Departemen of Economic and Social Affairs, editor. United State of America: United Nations. 
TAHUN [MANUJU: MALAHAYATI NURSING JOURNAL, P- ISSN: 2655-2728

2021 E-ISSN: 2655-4712 VOLUME 3 NOMOR 4 TAHUN 2021] HAL 587-599

Utari, W., \& Novayelinda, R. (2013). Efektifitas Pendidikan Kesehatan Terhadap Peningkatan Pengetahuan Keluarga Tentang Infeksi Saluran Pernapasan Akut (Ispa) (Doctoral Dissertation, Riau University).

Yatnikasari, S., Pranoto, S. H., \& Agustina, F. (2020). Pengaruh Pengetahuan Dan Sikap Terhadap Kesiapsiagaan Kepala Keluarga Dalam Menghadapi
Bencana Banjir. Jurnal Teknik, 18(2), 135-149.

Yulianto, E. (2019). Manajemen Pembelajaran IPA menggunakan Media Audiovisual di Sekolah Dasar. In Prosiding Seminar Nasional Manajemen Pendidikan (Vol. 1, No. 1).

Zuriah, Nurul. (2008). Pendidikan Moral dan Budi Pekerti dalam Perspektif Perubahan. Jakarta: Bumi Aksara 